\title{
Head and Hand: Rhetorical Resources in British Pedagogical Writing, 1770-1850
}

\section{Citation}

Shapin, Steven and Barry Barnes. 1976. Head and hand: Rhetorical resources in British pedagogical writing, 1770-1850. Oxford Review of Education 2(3): 231-254.

\section{Published Version}

http://dx.doi.org/10.1080/0305498760020303

\section{Permanent link}

http://nrs.harvard.edu/urn-3:HUL.InstRepos:3353818

\section{Terms of Use}

This article was downloaded from Harvard University's DASH repository, and is made available under the terms and conditions applicable to Other Posted Material, as set forth at http:// nrs.harvard.edu/urn-3:HUL.InstRepos:dash.current.terms-of-use\#LAA

\section{Share Your Story}

The Harvard community has made this article openly available.

Please share how this access benefits you. Submit a story.

Accessibility 


\title{
Head and Hand: Rhetorical Resources in British Pedagogical Writing, I770-1850
}

\author{
STEVEN SHAPIN and BARRY BARNES
}

All pedagogical writings and theoretical treatments of the process of education tend to be developed on the basis of particular conceptions of the constitution of the mind, the nature of thought, and the relationship of knowledge and thinking. Such conceptions may take the form of explicit psychological theories, or they may be informal, taken-for-granted models and presuppositions to which appeal is routinely made as arguments proceed. In what follows we shall examine these conceptions as they are manifested in a selection of educational writings of the period 1770 to I850 in Britain, and we shall show how they were employed both to devise and to justify educational programmes. ${ }^{1}$

The writings of this period and place make a particularly interesting case study, since they derive from a context characterized by rapid innovation in education, when intense concern with pedagogical problems was felt by a wide range of upper and middle-class groupings. The rapid changes in the distribution of wealth, power and social standing induced by the processes of industrialization had stimulated a re-appraisal of the functions and effectiveness of existing educational provisions and a search for new forms and institutions. Writers frequently laid bare their assumptions and cognitive models, as well as their goals and interests, in an unusually clear and distinct fashion.

While we use historical materials, our intention is not simply to offer a study of a particularly accessible historical context. Rather, it is to use the context, and the material selected from it, as a forum wherein to raise some issues evidently of general significance in the understanding of pedagogical writings. The general predicament of pedagogy is that it is bound to proceed on the basis of assumptions which are difficult to develop and correct via empirical feedback, and which are peculiarly liable to be influenced by social interests and conceptions of the social order. By observing this in our chosen context we put ourselves in a better position to consider how we might take account of this continuing problem.

\section{MENTAL TYPES}

Although the educational writings with which we are engaged differed widely in their interests, their analyses of the role of education, and the programmes they advocated, they were in remarkable agreement upon the general features of the mentality of the subjects of those programmes. To be more precise, the agreement concerned their mentalities, since, according to whether the 'higher orders' or the 'lower ranks' were being considered, adults were credited with one or other of two well-defined types of mentality. ${ }^{2}$ As would be expected, our writers, being representatives of the dominant sectors of society, accounted themselves mentally superior to the lower orders by reference to their 


\section{Oxford Review of Education}

own superior mentality and the contrasting mentality of those below them, which accounted for their 'stupidity'. There is nothing especially significant in this alone, but the precise categories used to characterize the contrasting mentalities are of considerable interest.

We can identify three central dichotomies employed to effect this contrast. The first sets the sensual and concrete character of the thought of the lower orders against the intellectual, verbal and abstract qualities of the thinking of those above them. Not surprisingly, given that our writers all to some extent gained standing from their verbal skills, this characterization amounted to an assertion of the worthlessness of the mentality of the masses. Just as their behaviour was condemned as sensual and debauched by middle-class moralists, so too was their thought condemned, often in the same breath. In a typical formulation, the surgeon-reformer Gaskell, treating of the immorality of factory hands, explained that their "mind does not keep equal pace with the body . . . Its better qualities are destroyed by the preponderance of animal sensations", thus providing a constitutional basis for the alleged sexual depravity of the industrial work force. In coping with that force, "it must be remembered that the mind of the mill artisan is little disposed to intellectual pursuits". ${ }^{3}$

Concrete sensual thought was too superficial to lead one to truth and, therefore, it could hardly furnish a sound basis for conduct. The pseudonymous 'Country Gentleman', a conservative polemicist against popular education in the I820s, put it most succintly: "Truth is said to lie at the bottom of a well, not on the surface: in other words, whatever appears only superficially right, is probably wrong." ${ }^{4}$ To attain truth one needed the ability intellectually to go behind appearances, to penetrate by use of the abstract intellectual faculties to the realities which lay behind the mere sensual appearances on the cave wall. On the other hand, cognition governed by the senses and not by the intellect could only be 'superficial' and, therefore, an inadequate surety for ethical behaviour. How could proper conduct be expected from

\footnotetext{
"Beings who have hardly ever once ... made a real effort to direct and concentrate the action of their faculties on anything abstracted from the objects palpable to the senses[?] . . . The abstracted, contemplative, and elevated ideas of the celestial happiness are far above their apprehension." ${ }_{5}$
}

The connection between the psychological and the moral diagnoses which their betters made of the lower orders' condition is evident. Because their minds were sensually governed, their thought was superficial; lacking internal structure, their thought was amoral. Hence, superficiality in thought and sensuality in behaviour are aspects of the same imputation. The contrast between the superficiality of the thought of the masses and the profundity of that of their betters is demonstrably a sub-theme of the central dichotomy set out above. And whereas superficial thought produced animal-like conduct, profound thought led to correct moral deportment.

This cognitive and moral inferiority of the lower orders 'Country Gentleman' regarded as the appropriate correlate of their menial position in the system of the division of labour:

"It may easily be shown that practice and theory seldom unite in the same individual; that the occupation of the practitioner requires all his time and thoughts to fulfil the wishes of eye or hand: whilst the theorist reasons within himself, and throws himself on his mind. Theoretical excellence must have reason for its soil, which mechanics have not." 6 
Nor, it should be added, did 'Country Gentleman' think it proper that practice and theory should be united in particular individuals, or that mechanics should possess theoretical excellence.

The second central dichotomy to be noted is that between the simplicity of the thought of the lower orders and the complexity of that of their betters. Again, the contrast had, for our writers, an immediate and obvious evaluative connotation. Those whose thought lacks richness of detail, variety or the capacity to apprehend and appreciate the relations between varied phenomena are indeed still said to be 'simple-minded', with the identical evaluative implication. The masses evidently could not perceive those relationships between phenomena which the higher orders took into account to direct their actions coherently for the long-term good. Their heads were crowded with "trifling and currupting ideas"; "they think nothing at all about their existence and life in any moral or abstracted or generalizing reference whatever". ${ }^{7}$ Their thought was immediate and lacking in potency, in contrast to the connected chains of inference characteristic of the thought of their superiors.

If it suited the writer's purpose the simplistic and sensual thought of the lower orders could, without abandoning its characterization as inferior, be celebrated as appropriate. The simple, immediate and concrete thought of the peasant is well-known from the romantic idyll tradition, and similar celebrations of the wit and sense of a 'contented' proletariat appear in the conservative literature of the early nineteenth century. ${ }^{8}$ The native wit and natural 'wisdom' of the lower orders might be shown to be well-adapted to their lot, yet still qualitatively different from and inferior to the thought of the higher ranks.

From an imputation of simplicity it was easy for our writers to represent the thought of the lower orders as actually or potentially unbalanced. The connection could be made plausible by invoking the informal faculty psychology which was widely accepted in the nineteenth century, whether in reified form as phrenology, or in some longer-standing, more abstract variant. The human mind was constituted out of a variety of cognitive faculties; either these would receive proper exercise, or, failing this, they would fall into disuse, upsetting normal balance between their working. In the characteristically simplistic thinking of the lower orders many faculties would indeed appear under- or unemployed. Their mentality would therefore lack the balance between faculties, and consequent stability, of that of their betters. Thus, left to themselves, the manufacturing classes were, according to the infamous Andrew Ure,

". . . the slaves of prejudice and vice; they can see objects only on one side, that which a sinister selfishness presents to their view; they are readily moved to outrage by crafty demagogues ..."9

Because his mental processes were (or had been made) unbalanced, the worker could easily be, as Henry Brougham and many others warned, "tossed to and fro by the sleight of men"; his moral, economic and political behaviour was therefore volatile. He was prone to superstition and credulity. Lack of balance was particularly stressed by those writers who saw a need to intervene and modify the thought of the lower orders by the imposition of some form of educational regimen.

As with the sensual character of thought, so was its simplistic nature amongst the lower orders linked to the division of labour and associated with the existence of differentiation and the routinization of tasks. Conservative writers were generally content to note an association of mentality with position in the hierarchy of skills. But for 'bourgeois' writers that hierarchy took on explanatory significance in environmentalist accounts of the creation of mental characteristics. Such accounts could legitimate radical or reformist 


\section{Oxford Review of Education}

polemics, in which case an optimistic view of the possibility of reversing the influence of environment was typical. Or they could be presented as matter-of-fact diagnoses, without a great deal of concern for how the social and economic order might be changed. The epitome of such 'disinterested' analysis is Adam Smith's Wealth of Nations, the educational remedies of which profoundly influenced Henry Brougham fifty years later. "In the progress of the division of labour", Smith said,

"the employment of the far greater part of those who live by labour, comes to be confined to a few very simple operations; frequently to one or two. But the understandings of the greater part of men are necessarily formed by their ordinary employments. The man whose whole life is spent in performing a few simple operations, of which the effects too are, perhaps, always the same, or very nearly the same, has no occasion to exert his understanding or to exercise his invention ... He naturally . . becomes as stupid and ignorant as it is possible for a human creature to become". ${ }^{10}$

And with perfect consistency Smith accounted for the general intellectual skills of elites in the same environmentalist terms as those which explained working-class simplicity and moral 'torpor':

"The employments, too, in which people of some rank or fortune spend their lives, are not, like those of the common people, simple and uniform. They are almost all of them extremely complicated, and such as exercise the head more than the hands. The understandings of those who are engaged in such employments can seldom grow torpid for want of exercise."11

From the great reformer Kay-Shuttleworth we have an impassioned identification of the factory system as the effective cause of lower-class simplicity and immorality:

"The dull routine of a ceaseless drudgery, in which the same mechanical process is incessantly repeated, resembles the torment of Sisyphus ... The mind gathers neither stores nor strength from the constant extension and retraction of the same muscles. The intellect slumbers in supine inertness; but the grosser parts of our nature attain such a rank development. To condemn man to such severity of toil is, in some measure, to cultivate in him the habits of an animal."12

The 'unnatural' and enforced disuse of some of the higher of the mental faculties was a stock resource, the invocation of which enabled nineteenth-century phrenologist-reformers like George Combe and John Conolly to indict the general character of industrial society as the cause of working-class stupidity, immorality and insanity. ${ }^{13}$

Finally, the third central dichotomy, already alluded to in some of the quotations above, concerns the active use of knowledge and experience by the higher orders, contrasted with the passive and automatic way in which the lower ranks were assumed to react to experience. Things simply happen to the lower orders; material is impressed upon their minds. And this diagnosis is the same whether the 'influence' is an iniquitous social order to be reformed, a uplifting course of education to be prescribed, or a crafty demagogue to be guarded against. The sensually-based, superficial and simple thought of the lower orders did not allow them to produce mediated responses to experience, or to make deep connections between different pieces of information, such as would permit them to be generalized for use as resources in a wide range of contexts. This was the diagnosis which justified the characterization of their learning process as passive and mechanical; facts and ideas entered their minds by absorption. In contrast the higher orders could, as we have seen, incorporate perceptions, knowledge and information into coherent systems of 
thought and sequences of inferences. By so doing, they could, on the one hand, extend their range of applicability, and, on the other, bring a range of abstract principles and symbolic operations to bear upon them. Thus, they could, unlike the lower orders, make active use of knowledge and experience; whatever it was, it served to extend the possibilities of their thought. In society, as in the body, the head was reflective, manipulative and controlling; the hand, unreflective, mechanical, determined by instructions. Thus, even where the lower orders were found troublesome, their restiveness was not dignified by treatment as active opposition, a rational response based on their real interest; it was, as we have noted, deemed the result of "volatility"- they were "tossed to and fro by the sleight of men".

We are now in a position to tabulate the characteristic properties of the two distinct types of mentality which stand in polar opposition to each other and which were routinely used to distinguish the thought of the superior portion of society from that of the masses. For ease of reference, and acknowledging Platonic and Aristotelian debts, we shall designate them the gnostic and banausic mentalities. ${ }^{14}$

\begin{tabular}{ll|l}
\multicolumn{3}{c}{ MENTALITY } \\
Thought & Gnostic & Banausic \\
& Intellectual & Sensual \\
& proftract & concrete \\
& verbal/symbolic & superficial \\
non-verbal/non-symbolic \\
& Complex & Simple \\
& harmonious & unbalanced \\
& stable & volatile \\
& mediated & direct \\
\hline Responses & Active & Passive \\
to & volitional & automated/mechanical \\
Inputs & purposive & lacking in purpose
\end{tabular}

Whatever their other differences, our writers tended to share these model forms of mentality as resources for use in articulating, developing and justifying their educational views, although as we shall see the range of uses to which they were put was rather wider than we have so far implied.

\section{KNOWLEDGE AND CONTROL: THE THREE HIERARCHIES}

All our writers, indeed practically everyone of our period whose views on the subject are known, assumed a correspondence between the social heirarchy, on the one hand, and the distribution of mentalities and knowledge, on the other. ${ }^{15}$ Those possessing the gnostic mentality ruled those of banausic mentality-the head ruled the hand. And those who ruled knew more, and knew more of significance, than those whom they ruled. As one moved up into the higher ranks of society, one increasingly encountered more abstract, refined and complex modes of thought, and more extensive, finely-structured and profound bodies of knowledge. Society was a triple hierarchy-of authority, of mentality, and of knowledge.

It was also agreed that such an association of hierarchies was essential in any stable society. But on the matter of the relationship between the three hierarchies and the manner in which they determined and sustained each other there was considerable 


\section{Oxford Review of Education}

divergence of opinion. There were writers at this time, particularly among the ranks of conservatives and those who represented the landed interest, who assumed that the distribution of knowledge was derivative of the hierarchy of authority, or that it was constrained into correspondence with a divinely-ordained, unalterable distribution of authority and fixed mentality. It was given to the head to control and to the hand to respond, and the nature of both was fixed and immutable, in society as in the body. Knowledge simply distributed itself as it was capable of being understood-the complex and profound at the top, the simple and superficial at the base of society. The hierarchy of knowledge derived from the other fixed hierarchies. ${ }^{16}$

But this position was little in evidence among writers actively concerned to justify the value of education and argue for the wider diffusion of knowledge. For the advocates of educational interventions knowledge was a commodity to be sold, and it had to be granted a potency of some sort. Similarly, those opposed to popular education, or politically opposed in general terms to its advocates, typically spoke of the pernicious consequences of the diffusion of knowledge, in order to present the most persuasive case possible. ${ }^{17}$ Thus, in the debates over the wider diffusion of knowledge it was commonly assumed that the hierarchy of knowledge could, at least to some extent, affect the stability of the other two hierarchies. Knowledge 'properly distributed' could reinforce and sustain the social order; knowledge 'improperly graded' or 'out of place' could lead to social conflict and the erosion of due deference. It was essential to social stability (even, or especially, in the views of popular educationalists) that the lower orders be less knowledgeable, that they possess an 'appropriate', and inferior, quality of knowledge.

The precise grounds for accepting this principle, and the detailed accounts of how knowledge and its distribution affected the other two hierarchies, varied widely. According to their aims and interests, and the existing accepted presuppositions of their cultures and contexts, writers constructed appropriate theories of the connections between knowledge, mentality and behaviour. By reference to these theories they advocated their programmes and denounced those of their opponents. The two mentalities were exploited as cultural resources in a whole range of arguments, theoretical structures and models of social order. It was important to stress that there was no limit on the way in which these resources could be used, and there was no necessary connection between the interests of a writer and the kinds of theory he constructed out of these resources. That such resources were employed is of more general significance than details of particular instances showing how they were employed.

It might be assumed that banausic and gnostic mentalities were permanently fixed by nature or by God, whereupon the power of knowledge would be linked to the function of relating the mentalities. Properly distributed, it could operate as a symbolic display of social standing, enabling the various orders better to recognize the hierarchy and the sectors to which deference was due. And it might also serve as a medium enabling communication between the top and the base of society, a vehicle through which the head could control the hand. Incorrectly distributed, knowledge could stimulate the masses to aspire upwards and give them the resources to use in doing so. Although, perhaps, their natural inferiority would doom these aspirations to ultimate failure, the temporary turbulence would be troublesone and inconvenient. Alternatively, it might be supposed that the mentalities were interconvertible, and, to some extent, the product of knowledge itself. From this it could be argued that unreliable, volatile banausoi might be rendered responsible, stable gnostics by appropriate education, or, conversely, that dangerous, hostile banausoi might be converted into even more dangerous hostile gnostics. ${ }^{18}$ The natural extension of this controversy was for one side to distinguish kinds of knowledge, and to impute to them different forms of efficacy: there was knowledge which imparted 
the admirable active mentality of the elite; knowledge which reinforced and controlled the banausic mentality and determined its operation; knowledge which filled the minds of the banausoi and prevented the intrusion of dangerous propaganda-of ideas originating in the heads of dangerous radicals, capable of determining the automated social hand and perverting its activity. Conversely, the opposition to this view would deny the existence of such different kinds of knowledge: whatever it was intended for, knowledge would be used by the banausoi as a general potentiating competence; they would twist it to their own ends, turn it upon its donors, use it as a resource. That which was intended to resstrict the mind would be found to develop or even demonically transform it.

All these arguments, and many more, were thrown up in the context of political debate over the scope, nature and role of education; it would be the task of a much longer paper to attempt a full taxonomy. They are a tribute to man's skill and endless creativity in the construction of rationalizations and adaptation of cultural resources to the exigencies of concrete situations. And it is as situated responses to particular polemical requirements and not necessarily as the coherent philosophies of individuals that we must treat these materials. We cannot expect the different arguments of particular individuals always to add up to some consistent, systematically-organized whole. They rarely do; but they are not, by 'failing' as philosophy, less worthy of serious attention.

Let us now flesh out this provisional taxonomy with a number of concrete instances. Among many explicit discussions of knowledge as a means of relating the two mentalities and symbolically reinforcing their heirarchical relationship, one finds that of the Scottish professor and educationalist James Pillans. He clearly linked social order to the distribution of knowledge along its hierarchy:

"If there is any chance of the frame-work of society being strained or disjointed in consequence of the progress of popular instruction, it is not from the diffusion of knowledge that the danger is to be apprehended, but from the higher ranks being left behind in the race of improvement."19

This linkage he explained by holding the possession of knowledge to be a necessary symbolic requirement in asserting and displaying status. Acknowledgement of the higher orders' superiority depended upon their effective display of "superior acquirements". "Superior knowledge" and "ease of manner", "gracefulness of deportment" and "varied accomplishments" result in "a charm [being] thrown over the character and outward bearing, which, more than anything else, captivates and subdues the great mass of mankind ...". Pillans' colleague, the moral philosopher John Wilson, similarly argued that "it is, after all, by mind alone that the high-born can maintain their right unquestioned", and that only by advance in knowledge "can the peasant lift himself up to the level of the peer". Changes in knowledge could, therefore, be adduced as explanations of social change, and the existing distribution of knowledge could likewise be given as an account of the social hierarchy. Of the the higher classes, Wilson assured his readers that "instructed they must be, for their knowledge gives them their rank [and] makes them feel it ....".20

'Country Gentleman', strenuously objecting to the extension of adult education through Mechanics' Institutes, also insisted on the necessary connection between the hierarchy of knowledge and the social hierarchy. To increase the knowledge of the lower orders would be inevitably to make them desire to rise in society to the level appropriate to their new intellectual state. And to do so would also be to provide them with the means of rising, for knowledge was a dangerous resource, possession of which might tempt them to transform a perfectly satisfactory and stable social order into the pathological state of democracy. ${ }^{21}$

The contention that 'secular' knowledge (as opposed to 'moral' knowledge) had the 


\section{Oxford Review of Education}

character of a resource was central to the conservative position of Sir Archibald Alison of Edinburgh, who took it as grounds for opposing Whig pressure for the wider diffusion of secular education. To provide knowledge without religion, said Alison, gave power and freedom of choice to human beings whose basic nature was evil and depraved. In the past this tendency had corrupted the great and the affluent; today it would corrupt the masses:
“... Human nature in all ranks is the same; ... knowledge is power to all, but wisdom only to those who use it rightly; ... so far from mere secular education being an antidote to evil, or a preservative against the progress of social corrup- tion, it has the greatest possible tendency to increase both, if not restrained by the force of moral precept, and sanctified by the simultaneous spread of religious instruction." 22

[Thus this legal gentleman identified the moral commodity in which he dealt as an effective source of control, and the commodity in which Henry Brougham dealt as a source of demonic power to the masses.]

Alison and 'Country Gentleman' offered articulate and interesting variants of conservative argument against popular education, especially as it was conceived by the supporters of the Mechanics' Institutes and the Society for the Diffusion of Useful Knowledge. Alison saw real problems of social control in society which needed to be dealt with by the extension of religious instruction and practices. Wherever religion was not, there knowledge increased evil; as religion was weakest among the masses, there knowledge should be disseminated least of all. Everywhere knowledge was a resource people would bend to their general aims; and when people were unconstrained by religion, these aims would, of necessity, be evil. In contrast, 'Country Gentleman' painted a picture of an idyllic state in which the "uneducated labourer is ... happy in his contented hearth"- "His knowledge measured to his stateand place". There existed in Britain at that time, according to "Country Gentleman', a stable twin hierarchy of knowledge and status. The social hierarchy, from King to the 'Common People', was associated with a hierarchy of knowledge. It was traditional to confine "the superior sort of education to birth and wealth", but it was also essential to the stability of the social edifice that knowledge be graded before distribution. ${ }^{23}$

This, however, was a view not confined to 'Country Gentleman', but implicit also in the writings of his opponents, the advocates of popular instruction. They emphasized the dependence of the social upon the intellectual hierarchy by the very form of their denial of the charge that popular education tended to lessen due deference from the lower orders and "respectful deportment toward their superiors":
"By having a measure of knowledge, and of the power and practice of thinking, the people would be enabled to form some notion of what it must be, and what it is worth, to have a great deal more of these endowments. They would observe and understand the indications of this ampler possession in the minds of those above them, and so would be aware of the great disparity between themselves and these superiors. And since they would value themselves on their com- paratively small share of these mental advantages ...., they would be compelled to estimate by the same scale the persons dignified by so far surpassing a share of this admired wealth."24

An ignorant population would not even be able to recognize the scale if it were not ensured that, through education, they became its bottom element.

Analogously, others argued that, since the middling classes and higher ranks needed to 
keep 'due proportion', they would be stimulated themselves to advance in knowledgethus increasing the total stock of knowledge, the moral tone of society and the store of potentially useful information:

“... This pressure from below, which is created by attention paid to popular education, is sure to make the upper and middle classes take care of themselves and improve their own." 25

'Country Gentleman' could not agree:

"... If the working classes are to be taught the sciences, what are the middle and higher classes to learn, to preserve the due proportion? The answer is obvious enough. There is nothing they can be taught by which they can maintain their superiority. ..."26

Thus, practically all the writers involved in these controversies over the distribution of education invoked a necessary correlation of knowledge and authority within the heirarchy of any stable society. And they all held the manipulation of knowledge to be a means of manipulating the social order. Where they differed was in their assessments of the dangers involved in diffusing knowledge to the lower orders. Knowledge could be treated as potentially powerful, as a source of competence-either a direct resource in the acquisition of standing and political significance, or an indirect resource which brought power through wealth, as many nineteenth-century Baconians believed. Or its power might be thought to lie in its use as a symbol in the ritualistic display and celebration of hierarchy. And there were many more variants on the theme of knowledge as a dangerous potential source of power, and its distribution as a reinforcement of the social order.

How then was it that there was any pressure at all for the diffusion of knowledge? If all recognized that the social order was sustained by a hierarchical distribution of knowledge, why was it desired to impart more than the barest minimum of knowledge to the lower orders? Even if the risk of disturbing 'due proportion' was slight, why was it taken at all?

Part of the answer would appear to be that popular education could be taken as an experimental attempt at social control and stabilization by communities which perceived, or or thought they perceived, real breakdowns and weaknesses in the social order. 'Country Gentleman's' account of the social order as healthy and stable would appeal to those who indeed experienced it that way. In all likelihood, such groups would see a disturbance of the distribution of knowledge as a pointless risk. They would respond to a dramatization of this risk which spoke of the power of knowledge to stimulate desire and to provide the means to press upwards from the base of society. The advocates of popular education, on the other hand, perhaps because they were active in urban areas with rapidly-growing and far from docile working-class populations, represented society as already in an unhealthy and potentially dangerous state. The labouring classes evidently were not rendered subservient and dependent because of their ignorance. Rather they seemed thereby rendered vulnerable to the polemics of agitators and radicals, and susceptible to the temptations of the ale-house, gambling table and brothel. Could knowledge be exploited as a resource in social control, given that the lower orders left to themselves would otherwise turn to knowledge and develop ways of thinking which boded ill for the existing order?

'Country Gentleman' and Alison had rationalized concern with the disturbance of the distribution of knowledge by representing knowledge as a resource for the lower orders; it gave them potential; it might convert docile, impotent banausic mentalities into more dangerous and threatening gnostic ones. (Alison, it should be noted, regarded the masses as inherently incapable of 'genuinely' understanding intellectual knowledge, but he was so 
evidently concerned with the power their misunderstanding of that knowledge might give them, and with the dangers of their intellects thus transformed, that the point can reasonably be made.) The advocates of popular education, on the other hand, wished to experiment with knowledge as a source of social control. Accordingly, they represented knowledge as a resource capable of fixing the mentalities of a working-class population which was showing disturbing signs of independence. ${ }^{27} \mathrm{We}$ find them characterizing knowledge as something which could couple the masses to the control of those above, a "medium of complacent communication" between the head and the hand. ${ }^{28}$ And we find kinds of knowledge being proposed to $f i x$ the banausic mentality and limit the scope of its thought, to ballast it and make it less easily swayed by agitators, to fill it up so as to leave no room for radical ideas or other errors of wicked and depraved men, and to divert it so that it had less time in which it might be drawn to sensuous indulgences and political follies. ${ }^{29}$

To all these laudable aims the opponents of popular education replied with rich irony and scorn:

"The great error of the philosophical party . . . consists in this, that they supposed that what they took pleasure in themselves every one else would take pleasure in; and that Bacon, Newton, and Locke would prove as effectual a counterpoise to sensual allurements or guilty excitation in the whole labouring population, as it did in Herschel, or Brewster, or Babbage, or Whewell, or Professor Forbes, or Ivory, or such gifted spirits." 30

And with regard to the ability of popular scientific education to divert the lower orders from political activity, the Tony Alison quoted the marvellous response of some of their leaders:

"We are anxiously looking for a new system of social organization, in harmony with the lights of the age, and Lord Brougham thinks to stop our mouths with kangaroos." 31

\section{TWO TRADITIONS OF CHILD PEDAGOGY}

We have already seen how the two mentalities and the way they related to knowledge were exploited as resources in nineteenth-century controversies which were largely concerned with adult education. Now we shall turn to writings which are mainly concerned with the education of children and see there also the use of identical thought materials. Two traditions can clearly be discerned in the pedagogical writings of the period. One tradition was primarily related to the education of the children of the lower orders, the other with the instruction of the young of the higher ranks and newly wealthy middle classes. They both exploited the resources previously set out, because they took the social hierarchy as a metaphor for the educational hierarchy, at the foot of which was the child. Thus, the child was initially characterized as possessing a banausic mentality.

The first tradition was concerned with forms of knowledge and pedagogic technique most suited to banausic mentalities. It outlined the knowledge which made them most useful in society-that which the hand should possess to make it most responsive and useful to the head. It discussed the knowledge which would most effectively fix and stabilize their mentality and hence control their actions. And it considered the teaching methods most appropriate for communicating with such mentalities. We shall call this the banausic tradition because it was concerned with the education of banausoi, and not because it alone took the model of the banausic mentality as a resource in its thinking. Both the traditions to be discussed utilized this resource. 
The second tradition, concerned with the education of the superior portion of society, addressed itself to the problem of assisting the emergence and growth of gnostic mentalities. For this reason we shall call it the gnostic tradition of pedagogy. Insofar as the gnostic tradition was interested in the banausic mentality, it was interested in its transformation. The gnostic tradition considered the forms of knowledge and the pedagogic techniques which could best facilitate this transformation, and subsequently best exercise and extend the range of competences of the gnostic mentality. Unlike the banausic tradition, the gnostic tradition was little concerned with what knowledge its subjects required for the proper performance of their social and economic roles. The main thing was that they should acquire the compentences appropriate to the gnostic mentality, whereupon they would be able readily to learn and understand whatever knowledge they subsequently required. Knowledge in education was justified in this tradition as a vehicle for the transmission of general mental skills and competences. Science, mathematics, languages, or the perversities of grammar would be held to 'train the mind'. (Had we been dealing with the realities of educational practice rather than its rhetoric we should have had to consider and explain the remarkable differences between the two. For a great deal of the education of the elite centred on the mechanistic transfer of information, rote learning, and all the techniques held to be appropriate for the banausoi.)

Let us first consider pedagogical discussions of how knowledge and competence was supposed to be transmitted to the mind of the child. ${ }^{32}$ Many writers noted the importance of operating through the medium of children's sensory capabilities wherever possible, and eschewing appeals to abstract intellectual faculties, but the sensory avenue was most strongly stressed in the banausic tradition. The banausic tradition gave the sensory pathway a privileged position; it was held to be the easiest, or even the only way of making an inroad to the mind. The Quarterly fournal of Education, produced in the 1830 s by the Pestalozzian circles in the Society for the Diffusion of Useful Knowledge, favourably assessed the school at Cheam conducted by the Rev. Charles Mayo and his sister Elizabeth. "The mind of the child", the editors agreed,

"is very much under the influence of the organs of sense, and is continually drawn away from one object to another, as each successively presents itself". ${ }^{33}$

The controlled presentation of actual objects thus appeared as the core of the educational experience. In the Mayos' influential Lessons on Objects, which reached ten editions by I845, the 'object lesson' was the centre-piece of pedagogy. The chief aim was "to cultivate the faculty of observation, this being the first faculty developed in the infant mind". ${ }^{34}$ A similar policy was steadily pursued by the Edinburgh Sessional School for the urban poor, conducted by John Wood. Here it was made very clear that the study of common objects was an alternative educational base to the use of words, symbols and abstract concepts:

"... Never should there be too long and too scrutinizing an investigation into the mysteries of great discoveries and high sciences . . .; but rather agreeable descriptions and examinations of objects within the reach of their senses and understanding. . .." 35

The educational work of the Rev. Richard Dawes at King's Somborne among the children of the lower orders, like that of Wood and the Mayos, stressed the unsuitability of words and abstractions as educational media, and emphasized the propriety of studying 'common objects'. Dawes' explicit educational aim was, like that of almost all his fellow popular educationalists, an improved moral and religious condition among the lower orders, but, in order to approach this goal, it was necessary first, so to speak, to 'open up the mind'. 


\section{Oxford Review of Education}

This was accomplished through stimulation of the sensory pathway; the aim of the teacher should be "to make the children observant and reflective; to make them think and reason about the objects around them ...". ${ }^{36}$ Objects were, therefore, uniquely suited, and words and abstractions were peculiarly unsuited, to provide the foundation upon which the development of thinking among the lower orders could take place. ${ }^{37}$ Thus, by the middle third of the nineteenth century, an important tradition in educational thinking developed, which stressed the role of 'science' in the teaching of the young of the common people, but which was based in fact upon the presentation of a variety of natural and technical objects, accompanied by glosses upon their constitution, function, taxonomic position and moral significance. The role of science in this tradition was therefore clearly predicated upon a model of how the lower orders thought and how to gain access to their minds, in order then to achieve a variety of intellectual and moral objectives. ${ }^{38}$

However, where the banausic tradition stressed the role of sensation as the basis of knowledge, the gnostic tradition dealt with the senses quite differently. The sensory faculties were either of little significance; or their importance declined with one's progress through the curriculum; or they were an educational nuisance, sources of error and distortion which were not to be stimulated or developed. To transcend the banausic mentality the intellectual faculties had to be exercised and the sensual faculties left to atrophy. Maria and R. L. Edgeworth's Essays on Practical Education, "principally intended . . . for the higher classes of society", advocated extreme circumspection on the pedagogic role of objects and demonstrations. In reference to the teaching of physics, they defended the propriety and importance of using symbolic, verbal and abstract formulations:

\footnotetext{
"It requires no elaborate argument to prove that a boy, whose mind was stored with accurate images of external objects, of experimental knowledge, and who had acquired habitual dexterity, but who was unacquainted with the usual signs by which ideas are expressed, would be incapable of accurate reasoning, or would, at best, reason only upon particulars. Without general terms he could not abstract; he could not . . . reason upon general topics, or draw conclusions from general principles. ${ }^{39}$
}

Such a person would be in the position of someone who had to go through tedious calculations, rather than using algebra to solve a problem. The pedagogic moral was clear: sensually based forms of communication and learning had to be abandoned as soon as was practicably possible.

Knowledge might be presented in the curriculum of the gnostic tradition as progressing from the particular and concrete, but the ultimate end of essential knowledge (in the literal sense) had to be kept clearly in sight. "0 "The habit of abstraction", the Edgeworths argued, "is highly advantageous to the mind". One's progress "in real knowledge depends upon rejecting all that is superfluous". ${ }^{41}$ The individual's development, as well as the development of an entire body of knowledge, was represented as itself a process of abstraction, of moving from the particular to the general, from the concrete instance to the relational concept, of moving, thereby, upwards along the mental hierarchy. Thus, the gnostic pedagogical tradition, as contrasted with the banausic tradition, imputed to its subjects the mental capacity to cope with abstract concepts and to base their thought upon the process of essentializing knowledge away from the sensory, the concrete and the particular. The personal knowledge thus mastered and internalized is not merely different from that marshalled in the banausic tradition; it is regarded as indubitably better.

The second distinction between the banausic and gnostic traditions concerns the nature of the knowledge appropriate in educating the child. In the banausic tradition knowledge was stuff, something to be inserted into the mind, there to determine the behaviour of the 
passively responding banausic mentality. In the gnostic tradition knowledge provided the mind with a resource, and the more abstract and general it was, the greater was its potency as a resource. The more the gnostic mentality learned, the more it was capable of using knowledge as a resource, and, thus, the more it was a genuine gnostic mentality. This contrast is brought out by examining how the two traditions treated the educational role of the fact.

The Edgeworths, in prescribing proper pedagogical practice for the children of the upper orders, "strongly encourage[d] . . . teachers",

"to use as few precepts as possible in the rudiments of science, and to encourage

their pupils to use their own understandings as they advance". ${ }^{42}$

"The sciolist", they asserted, "has only learned to talk-we wish to teach our pupils to think, upon the various objects of human speculation". ${ }^{43}$ Facts, inculcated by rote, were unsuitable for the ends of the gnostic tradition: "... Let [the pupils] never be required to repeat in the words of the book ...; let them speak in words of their own, and arrange their ideas to their own plan ..."44

The same set of distinctions and practical injunctions suggested themselves to Professor James Pillans, who made the comparative social bases of the two traditions very plain. He criticized the technical ambition of much popular education, suggesting that failure in many cases was to be attributed to the vanity of efforts to initiate even the adults of the lower orders "into the mysteries of chemistry and astronomy". "Many of the attempts", Pillans said, "to enlighten the adults of the labouring classes . . . are of a cast too abstruse and scientific".

"On the other hand, a mistake of a different kind has been of late still more prevalent-that of overlaying the mind of the young aspirant to a liberal profession with the facts ascertained and the results arrived at by learned and scientific research, while he is left unacquainted with the steps and processes of the proof. . . . He should not be tempted to take all upon trust, on the ipse dixit of a lecturer, but should be put through such a course of mental gymnastics, as might enable him to climb the tree and gather the ripe fruit for himself. . ."45

His colleague, Professor Wilson, substantially agreed with Pillans' diagnoses. Knowledge might very well be crafted for purposes of symbolic display and personal development among the 'higher classes', but "with the poor, or inferior man, you wish to see something more solid in his knowledge ...". While one might envision teaching all social classes the same subject, it was essential to make pedagogic distinctions in the structure of the body of knowledge:

"Also, it is for many reasons very important, that discriminations be made in each [subject] between what it most certainly established, and what is conjectural and doubtful, presenting to [the lower orders] as much as possible the first and not the second." 46

Wilson explicitly justified distinctions in the two pedagogies on the basis of the subject's social and economic role. Of the lower orders, he said that

"Knowledge is not their business. ... Their business is to render a prescribed and taught, and, for the most part, a very simple, and a uniformly recurring labour. Their calling, then, is in a great measure independent of knowledge, except what is communicated to them in it. . . It is otherwise with the higher orders. . . . The sphere of their action is high and wide, and often demands, is always much the better of, general knowledge." 47 
So the role of the fact in the two pedagogic traditions was to differ. Usage might be rationalized by referring to notions of what the subjects' minds 'would take', or it might be justified by pointing to the use knowledge or competences would be to the recipients in their station and calling.

As far as the banausic tradition is concerned the lower orders needed facts, and facts should be inserted into their heads in the amount their educators felt appropriate. The recipients would passively accept the transmitted facts and their behaviour would subsequently be restrained by their awareness of the facts. The fixed banausic mentality lacked the capacity actively to exploit facts as instruments. No doubts are evident in the banausic tradition as to whether the factual knowledge would 'take'. In this tradition, knowledge is something that one 'puts in', because the mind of its subject is something into which one 'puts' things.

But no doubts were expressed among the writers in the gnostic tradition that the relationship of mind to knowledge was an active one. Knowledge was an instrument, not a made thing. The Edgeworths' formulation is illuminating:

"We are not solicitous about the quantity of knowledge that is obtained at any given age, but we are extremely anxious that the desire to learn should continually increase, and that whatever is taught should be taught with that perspicacity, which impresses the general understanding. . . ."48

The mind grapples with knowledge; it is active and manipulative. As Wilson said, 'the higher classes' look "upon knowledge as a great war which they are all carrying on together". The end of their education is "to animate" and "cherish" this feeling. ${ }^{49}$ They should feel, appropriately, that they march "in the van of the conquests of human intellect". The mind is agonistic; knowledge is a suitable antagonist on which one exercises one's muscles. To Professor Pillans, education for the higher classes

"... Must be a course of intellectual discipline, directed, not to stock the mind with ready prepared information, but to bring out in orderly and healthful succession the several mental faculties, to give each its appropriate nourishment and invigorating exercise, and to teach the possessor the free and dextrous use of them all. . .." 50

Pillans too linked pedagogical prescription to social role:

"In this case, the point to be aimed at it not a great store of knowledge of which the mind is little better than a passive recipient. The legitimate object of higher education is, to provide the means of evolving and perfecting the various powers and capacities of man's nature, so as to enable him, in the words of Milton, 'to perform justly, skilfully, and magnanimously, all the offices, both public and private, of peace and war'." 51

In the gnostic tradition, knowledge potentiates; it does not determine.

The determining character of knowledge and the assumption of a receptacle mind in the banausic tradition is indicated by the replacement theory to which so many advocates of popular adult education subscribed. By filling the mind with useful and innocent knowledge, it was argued by popular educationalists that there would be less room for 'brutalizing pursuits', that the recipients would be fenced "against the seduction of low and sensual indulgences". "But in the liberal education", Pillans said,

"the question is not, how shall [we] fill up most agreeably an idle hour. It is, by what means we shall best secure the general and, up to a certain point, equable cultivation of the intellectual powers. . . ." 52 
The practical pedagogical instruments to achieve this balanced cultivation of the gnostics' intellectual faculties might vary from context to context, although many educationalists were convinced that certain 'subjects' were inherently superior for the purpose. Traditionally, the study of dead languages and ancient forms of mathematics have been argued to be 'good exercise for the mind'. In the Scottish situation, it was often geometry which possessed this unique arcanum; algebra and analytic mathematics were merely mechanical. ${ }^{53}$ Professor Wilson wished the elite to continue to study Greek, Latin and Hebrew, "were it only for the subtle cultivation of intellectual power that is obtained in the mere acquisition of them". ${ }^{54}$ The particular connections which have existed between each pedagogical tradition and specific bodies of knowledge is a subject we cannot take up here. One may suggest that any and all subjects, taught in any and all actual manners, can be argued to be 'good exercise for the mind'. What one may be seeing is the rationalization of traditional pedagogical practice, rather than the disinterested identification of especially appropriate bodies of knowledge. ${ }^{55}$ The central notion in the rhetorical formulations we have just displayed is not the 'subject', but the portrayal of an active, intellectual and voluntary mind juxtaposed to knowledge in the gnostic tradition, and a passive, sensual and determined mind in the banausic tradition.

\section{THE BASIS OF THE THOUGHT MATERIAL}

Both in the debates about the wider establishment of adult education, and in writings on the teaching of children, we have now observed the utilization of a basic set of shared cultural resources or what we may call 'thought materials'. In all the diverse and conflicting writings two kinds of mentality were invoked, the banausic and the gnostic, with opposed styles of thought and contrasting orientations to external sources of knowledge and experience. Through different accounts of the basis of these mentalities, and the extent to which they were transmutable by educational processes and by the transmission of various kinds of knowledge, arguments for and against a wide range of possible educational programmes were generated, and the alleged consequences of diverse courses of action were displayed. These arguments centred on the consequences of various programmes for the distribution of power and the stability of the social hierarchy, since education was, as always, primarily taken as a means of realizing political objectives.

Mainly because of the historical context which was chosen as a source of concrete materials, practically all our examples involved celebration of the gnostic mentality and denigration of the banausic. In a debate which focussed upon the desirability of educating the masses, alleged contrasts between the higher and lower orders of society were of central significance. Writers portrayed themselves and their peers as gnostics, and the masses as banausoi, in order to create and make visible a hierarchy of worth with which to justify a hierarchy of standing, wealth and privilege. The use of the two mentalities as resources in argument and justification is not, however, restricted in any way; they can be deployed in whatever fashion people find expedient, and they have been deployed in the past in ways which contrast strikingly with those usages illustrated above. At times, for example, the banausic mentality has been celebrated by polemicists, and held to be the superior of the two mentalities.

Emergent groups, struggling against entrenched elites, have been particularly given to rhetoric of this kind. Frequently, they have celebrated the qualities of the 'hand', and assailed the sterility, vacuousness and abstraction of the thought of the 'head' in their society. They have valued the senses as direct sources of authentic knowledge, and developed empiricist, inductivist epistemologies with which to condemn the abstract, speculatively-based knowledge of the elite they were seeking to discredit. And they have 


\section{Oxford Review of Education}

asserted the value of practical manipulation, observation and experimental procedures as tests of the validity of knowledge, in order to deride the cloistered, contemplative life of the spirit so often held as the ideal among orthodox intellectual elites. Among the many such iconoclastic groups who have so celebrated the 'hand' we can point to the Paracelsians of the late Renaissance, the Baconian polemicists of seventeenth-century England, and the phrenologist-reformers of early nineteenth-century Britain and the United States. ${ }^{56}$

Similarly, the two mentalities have been used as resources by those who have set the main thrust of their rhetoric against attempts to identify two distinct kinds of individuals in society. Such writers have tended to take the mentalities as aspects or potentialities of the psyche. All people are both gnostic and banausic naturally or potentially; the differences or apparent differences between individuals are either illusory or the products of social contingencies. The work of the phrenologist George Combe is a particularly good instance, from our period, of rhetoric of this kind; but, as we should expect, it tends to appear in conjunction with many kinds of argument for ameliorative reform. ${ }^{57}$

The two models were, then, capable of being used in an endless variety of ways, and actually were used in very many. It is not our central concern here to catalogue the observed range of uses, or to suggest when and in what circumstances one or other mode of use is likely to occur. What we want to make significant, and to direct curiosity towards, is the fact that the two models were used, time and again, in argument after argument, polemic after polemic. For the models cannot be taken as analogous, say, to ideal-typical descriptions of animal or plant species, confirmed and repeatedly supported by empirical evidence. We are encountering here a particularly interesting kind of stereotype. The characteristics of the mind are evidently entities which members of all cultures 'know' about, and confidently 'know' about, quite apart from their personal experiences, or theories of scientific method, or sensitivity to the problems of psychological investigation. Our writers were typical in that they confidently referred to mental types, expecting to be believed, and feeling no need to cite empirical evidence or personal study and investigation which supported their commentary.

In all societies, as people interact, order themselves, ally and oppose each other, exploit each other and support each other, imputed mental characteristics emerge and become institutionalized as rationalizing structures, which can be turned to as reasons and legitimations for action, or for explaining why things are as they are. Those who occupy positions towards the top of a hierarchy almost universally employ two general strategies among those which they use to justify themselves. One is to appeal to naturalistic justifications of the division of labour laid out below them; the other is to employ the analogy of the body to enrich and reinforce their naturalistic justifications. ${ }^{58}$ Thus, in the materials cited above, the activities at the various levels of the division of labour were transformed into modes of thought, and types of mentality and mental competence. Roles, socially required operations, become mental characteristics, intrinsic features of persons. That which men were obliged to do, or privileged to do, became that which men were fitted for. And the whole scheme was coloured by the image of head and hand which so appropriately expressed the structure of the division of labour and its hierarchical arrangement. Thus, we might say that these writers 'knew' men's minds because they 'knew' their social roles; and they 'knew' them in such detail because they 'knew' that the head controlled the hand and what were the characteristics of the one and the other. These writers knew what most men with an interest in sustaining a particular social heirarchy and division of labour know. Gnostic and banausic mentalities have been known to many men in many cultures.

As educationalists and as purveyors of knowledge, however, these writers also projected the features of the types of thought onto the knowledge characteristically possessed by 
the two kinds of thinkers. We find 'high' knowledge and 'low' knowledge: the one abstract, symbolic and complex, a resource for thought; the other concrete, direct and simple, a constraint and determinant of thought. And we find the typical assumption of educationalists that knowledge is powerful, and that the hierarchy of knowledge is of at least equal significance to the other two hierarchies of authority and mentality. In the perennial debate between idealism and materialism, the teacher, the scholar and the intellectual have always been moved by their social interests towards the defense of ideas; even self-professed Marxists in modern times have been hard put to it to resist idealism, if they occupied academic or intellectual roles.

Thus, the supposed mentalities and the properties of knowledge invoked by the educationalists in our context cannot be understood as empirically-informed hypotheses, checked and developed by experience and investigation. This is not to say that the inputations were nothing more than wish-fulfilment, or that the writers in question paid no attention to empirical reality and what they were manifestly capable of observing in their social context. On the contrary, the imputations doubtless were related to empirical observations, and probably were found to offer plausible accounts of them. They did successfully make sense of much social experience and organize it theoretically. The point is that the way sense was made has to be understood in terms of the character of the social hierarchy, and the situated interests and experiences of writers and polemicists within it. And, more importantly, the resources out of which sense was made were constructs of a kind which we find generated in most social orders as bases for legitimation and rationalization.

What general conclusions can be drawn then about the use of the two constructed mentalities in pedagogical theorizing? It is tempting to dismiss them as devices of polemicists and writers lacking real sympathy and curiosity with respect to the subjects of education. But this would be unfair in some cases at least, and, more importantly, it would underestimate the general predicament of pedagogical thought. All thinking, even the most esoteric, technical and non-evaluative, must draw upon existing concepts, beliefs, models or images as resources or raw materials. It must develop and test theories created from available systems of meaning. And practically all the thought materials relevant to the conceptualization of pedagogical questions is already bound up in rationalizing structures and existing informal claims which everybody routinely makes about others' minds, thoughts, beliefs and so on. If we may so put it, current empiricallyinformed pedagogy is obliged to use the same thought materials as the rhetorical pedagogy we have displayed. To proceed it must first plunge into the morass of rationalizations and informal models which currently exists. Hence, it is endemically susceptible to influence from and interaction with forms of culture generated to fulfil rationalizing functions. And even it it could be cut off from this interaction, it is unclear to what extent theories of pedagogy could be 'filtered' and 'purified' by exposure to empirical feedback. Desirable though such feedback may be, however does one identify the point at which it entitles one to forget the resources employed in the construction of one's theories, and proceed as though they were the simple truth?

To emphasize that such questions are neither trivial nor esoteric, it is worth noting just how much of current educational thinking is structured by the very categories which have proved so significant in the historical works cited above. The concrete/abstract, sensual/symbolic dichotomies, for example, continue to run strong in psychological work on intellectual development, child learning and intelligence testing. Piaget's work, and 'Piaget's theory' as an institution cited and believed in by educationalists, centres right upon them. The tradition of IQ testing and its opposition have fought for a long period over issues defined in the same way; a contemporary instance is the controversy generated 


\section{Oxford Review of Education}

by Arthur Jensen's recent comments on the contrast of associative and conceptual learning and their respective merits for the disadvantaged. ${ }^{59}$ Similarly, in educational sociology Basil Bernstein's work, which represents the only developed theoretical discussion of educational knowledge and pedagogy, is concerned to explore how the social organization of knowledge in curricula, its internal intellectual connections and boundaries, their strength and rigidity, the linguistic codes in which knowledge is transmitted, and its factual/analogical qualities can all contribute to the maintenance of social order, both in the immediate context of the educational institution and, indirectly, in the wider society. ${ }^{60}$

Similar themes have diffused through the social sciences generally. They are present, for example, in the long tradition of sociological writings on reification. The central themes of this tradition are found in a particularly refined and extreme formulation in the work of some currently active 'ethnomethodologists'. They warn us against the way that so-called 'objective knowledge' is liable to stultify and restrict the mind, and seek to neutralize this insidious influence by reminding us that knowledge is something which we ourselves actively create, one of our practical accomplishments. To allow oneself to be gripped and compelled by a sense of the external objective validity of positive science (and, particularly, orthodox sociology) is to place oneself among the banausoi, a fate to be avoided only by intense mental vigilance. ${ }^{61}$

Predominantly, however, it is not positive scientists who have been characterized as banausoi in the various social science disciplines, but the three great significant groups of 'others'-aliens, ancestors and deviants. ${ }^{62}$ The former provide the most obvious example, as they have been characterized in the literature of social anthropology. Earlier anthropologists characterized primitive thought as peculiarly concrete and sensual. Material objects and particular ritual acts played the role taken by abstract metaphysical principles in our own thought. All kinds of crude causal determinants explained the nature of their thought. Primitives were banausoi, and their thought, made out as essentially different in kind from our own, could be regarded as defective accordingly. More recently, it has been thought appropriate to value the thought of preliterate societies, and it has been treated accordingly as very much more like our own. The thought of the 'primitive' (who now increasingly exists between inverted commas) has been found to be suffused with gnostic features. In the work of Lévi-Strauss, for example, it emerges as remarkably logical and coherent, animated by intellectual curiosity and not 'merely' by use, inferior to our own intellectual operations only because it lacks the freedom of fully abstract conceptual thought and retains some of the restricting concreteness of the thought of the banausoi. ${ }^{63}$

If we are to think at all, we have to employ the thought materials with which our culture provides us, however 'tainted' we may find them to be. There is no escaping this predicament; indeed, this present paper is no more successful in escaping it than those writers with whom we have dealt. Hence, there is little point in criticizing the educationalist or the social theorist simply because he operates with particular materials. There is some point, however, in suggesting that we retain an awareness of the resources we employ in thinking, and the general character of our thinking and theorizing itself as bricolage. ${ }^{64}$

This suggestion should apply with particular force in the case of pedagogic theorizing for two reasons. First, the cultural resources we have to employ in this area inevitably link our thought with established structures of rationalization and make it vulnerable to our own unstated and, perhaps, unrealized informal conceptions of social order. Secondly, as academics we are very likely to possess a gnostic self-conception and to be all too ready to equate the banausic with the inferior. As a simple test of this propensity the reader may 
wish to reflect whether he suspects this paper to be either an 'attack' upon or a devaluation of the status of 'rational thought'. For such thought is explicitly treated here as bricolage. And the bricoleur, for all his ingenuity and creativity, remains of the banausoi.

\section{Appendix: Note on Sources and Methods}

One of the inspirations which prompted this paper was the work over the past four years of one of us (S. S.) on the diffusion of scientific culture and scientific education in Britain during the Industrial Revolution. It became apparent during the course of that work that there was great uniformity in the rhetorical arsenal people drew upon to justify the dissemination of scientific knowledge or principles. ${ }^{a}$ The study of nature was justified by constant reference to the 'natural order of things'. Our interest eventually turned to the rhetoric of justification itself-how it functioned and made sense to people, and the scheme of things to which the rhetoric corresponded. We became more concerned with how sense was made than with the more usual historical problem of what sense was made, and what in particular people were advocating through their rhetoric. This paper therefore lacks an important diachronic dimension: while identifying and examining certain conceptual structures, it does not set out to explain what particular measures were justified by their use, nor does it attempt to deal with changes in their deployment over time. It is hoped that the last section of the paper will go some way towards justifying the value of our 'static' approach.

Because we are dealing here with rhetorical formulations which we believe to be significantly homogeneous, certain difficulties may arise for the way in which we use sources and present quotations. Given that quotations are commonly displayed to provide unique access to the true state of affairs or to allow privileged insight into a writer's thoughts, our usage may seem unsatisfactory to some historians. The quotations displayed in this paper seem to us no better or worse than scores of other locutions found in the literature; one is as good as another; the individual's conceptual structure, in itself, is not germane to the reason we cite his thoughts. To have listed very many sources for each locution might have enhanced the historical credibility of our account, but at the risk of otioseness. Hopefully, those readers who have worked in this area will experience a sense of recognition.

Our selection of sources has, however, been governed by certain practical considerations. For one, we were concerned, so far as possible, to display material supplementary to the sources in our previous work on the functions of adult education in science. ${ }^{b}$ That paper has the aim of interpreting particular educational measures in contextual terms, and, ideally, should be read in conjunction with the present piece. Secondly, as we were not concerned with displaying the coherent philosophies of individual educationalists, we have not felt obliged to concentrate upon the utterances of 'great thinkers', or even to focus upon those writers who exerted 'influence' on the shape of educational innovations. But we were quite concerned to locate those rhetorical resources in most general circulation among the educated classes. For this purpose we made considerable use of an informal survey of the general periodical literature-the Edinburgh Review expressing the Whig views of the Brougham camp, Blackwood's that of the local Tory opposition, and the Quarterly Review that of the national Conservative consensus. The Quarterly fournal of Education was closely associated with Brougham's Society for the Diffusion of Useful Knowledge in the I830s. Both the reviews in these periodicals and the books and pamphlets noticed therein provide an insight into what notions structured the general debate over education in the first part of the nineteenth century. 
It is also a function of limited space that we have not attempted to provide a capsule history of the popular education movement in the period. For that we must refer to reader to a number of excellent surveys, and trust that the attempted generality of our thesis will be set against the lack of empirical background material.c

We must, however, provide very brief biographical notes on some of the less familiar writers whose views we cite:

Sir ARCHIBALd Alison (I792-I867): lawyer and historian, son of an Edinburgh Episcopal minister. An energetic contributor to Blackwood's Magazine and an optimistic, but staunch, Tory, who pointed out limitations to Malthus' laws and defended the necessity of slavery. As sheriff of Lanarkshire from I835, he had to deal with a series of serious riots and strikes, which he successfully suppressed.

MaRia \& RichaRd Lovell EdGewORTH (I767-I849; I744-I8I7): father and daughter; members of the 'enlightened' Lichfield circle around Erasmus Darwin and much influenced by the educational views expressed in Rousseau's Émile. R. L. Edgeworth's son was educated as Émile and so presented to Rousseau. Maria was a noted novelist, especially of works for children, and Richard was a member of the Board for Inquiring into Irish Education (I806-II).

JoHN FosTER (I770-I843): Yorkshire-born Baptist minister and essayist who contributed extensively to the Eclectic Reviez. He had practical teaching experience with both Irish and negroes. He disliked the corporate aspects of religion, and maintained diminishing republican sentiments throughout his life. His Evils went through five editions by the middle of the century and is perhaps the single most explicit source of psychological models which bear upon the debate over popular education.

'Country Gentleman': although widely cited by historians of education, no one, to our knowledge, has discovered his identity.

James Pillans (1778-I864): a student of Dugald Stewart and very close to the Whig Edinburgh Review circle. As Rector of the Edinburgh High School, he introduced the monitorial system. In I 820 he succeeded to the Chair of Humanity (Latin) at Edinburgh University, which he held until the year before his death. He gave testimony to the 1834 Commons Committee on Education and was a strong advocate of compulsory education.

JoHN Wilson (1785-I854): a lawyer, poet and, succeeding Dugald Stewart, Professor of Moral Philosophy at Edinburgh University. A strong Tory and the well-known 'Christopher North' of Blackwood's.

a See Arnold Thackray, "Natural Knowledge in Cultural Context: The Manchester Model", American Historical Review, 79 (1974), 672-709; Shapin, "The Pottery Philosophical Society, I819-1835: An Examination of the Cultural Uses of Provincial Science", Science Studies, 2 (1972), 31 I-336; Shapin and Thackray, "Prosopography as a Research Tool in History of Science: The British Scientific Community, I7001900", History of Science, I2 (1974), I-28.

b Shapin and Barnes, "Science, Nature and Control: Interpreting Mechanics' Institutes", Social Studies of Science, 7 (1977), forthcoming.

c Notably, David Layton, Science for the People (London, I973); J. F. C. Harrison, Learning and Living I790-1960 (London, I96I); Brian Simon, Studies in the History of Education $1780-1870$ (London, I960). 


\section{NOTES AND REFERENCES}

We should like to express our appreciation of many helpful discussions with Gary Soroka of the Edinburgh University Department of Politics.

I. Some notes on the background to these selections and the manner in which we have elected to use them are provided in the Appendix: Notes on Sources and Methods.

2. We are dealing here with actors' perceptions of where people are located on a social hierarchy, and it is therefore appropriate, so far as possible, to utilize their locutions'lower ranks', 'superior portion of society', and the like. The precise empirical referent is almost irrelevant for the purposes of our argument, and, quite probably, our actors meant different things when they used the same term. What is preserved is what is essential-actors' perceptions of relative position on a hierarchy.

3. P. Gaskell, Artisans and Machinery: The Moral and Physical Condition of the Manufacturing Population (London, I836), pp. 105, 246.

4. The Consequences of a Scientific Education to the Working Classes of this Country Pointed Out; and the Theories of Mr. Brougham on that Subject Confuted; . . . by a Country Gentleman (London, I826), pp. I7-I8.

5. John Foster, An Essay on the Evils of Popular Ignorance (New ed., London, I856; orig. publ. 1820), pp. 194, 196.

6. 'Country Gentleman', op. cit. (note 4), p. 5 In.

7. Foster, op. cit. (note 5), pp. 94, 96.

8. E.g., [David Robinson], "Brougham on the Education of the People", Blackwood's Edinburgh Magazine, I7 (1825), 534-551, esp. pp. 544-545.

9. Andrew Ure, The Philosophy of Manufactures (London, I835), p. 407.

I0. Adam Smith, The Wealth of Nations, ed. James E. Thorold Rogers (Oxford, I869), vol. ii, p. 365. (The editor of this edition notes that "mechanics' institutes, libraries and schools" have proved "a corrective to this sweeping charge". [fn. to p. 365])

I I. Ibid., vol. ii, pp. 367-368.

I2. James Phillips Kay, The Moral and Physical Condition of the Working Classes ... (2nd ed., London, I832), p. 22.

13. E.g., John Conolly, An Inquiry Concerning Insanity (London, I830), esp. pp. 99-100; George Combe, Lectures on Popular Education (3rd ed., Edinburgh, 1848), esp. pp. 24-25.

I4. In Plato's Republic (ed. F. M. Cornford, Oxford, I94I, ch. xxiv) he describes how the education of the Guardians commences with the world of appearances and only at its higher stages endeavours to detach the mind from the visible and lead it towards the forms and absolute ideas. Cognition consists of a hierarchy; the lowest form is totally governed by sensible appearances and the highest (noesis) has risen above them. Plato's educational programme is designed to ensure that the philosopher-rulers possess the highest forms of cognition. In Aristotle's Politics, Bks. vii-viii, the banausoi $(\beta \dot{\alpha} \vee \alpha \cup \sigma 0:)$ are the artisan and mechanic classes. They cannot be citizens because their work is ignoble and demeaning; it corrupts the minds of those who do it. To attain to the Good, the citizen requires leisure to cultivate the speculative parts of the rational soul. From the dictionary senses of gnosticism we wish for our purposes to retain the notion of knowledge as transcendent, while discarding any pejorative connotation

15. There were certainly those among the political elite who disdained knowledge and valued coarse displays of ignorance (the 'Squire' of the eighteenth-century novel was frequently so portrayed), but they tended not to write, hence their views are seldom encountered in a survey of rhetorical resources. 
I6. 'Country Gentleman' (op. cit., note 4) tends towards this position, but wants to identify Brougham's programme of extending knowledge as 'dangerous'. The Tory John Wilson is more in this tradition when he wrote: "Let not men . . . fear the effects of knowledge. It is a great power poured in, and will produce some commotion; but will settle and find its way to its proper places". The conservative could then find popular education innocuous if it suited his purposes, because, in the end, knowledge did not matter. [John Wilson], "Education of the People", Blackwood's Edinburgh Magazine, 27 (1830), I-I6, esp. p. 7.

17. This is evident, for example, in Tory reaction to Brougham's programme. Many Conservatives were unconvinced that education would have any substantial effect, but they very much feared a political alliance between the proletariat and the Whigs. This ambivalence is expressed, for example, by [John Bird Sumner and J. T. Coleridge], "Mechanics' Institutes and Infant Schools", Quarterly Review, 32 (I825), $410-428$.

I8. The standard social and political referent in the debate over popular education was the French Revolution. Was it an example of the consequences of diffused 'enlightenment', secular knowledge and materialism, or was it an illustration of the depraved actions engaged in by those kept in ignorance? Did improved knowledge cause social mobility, and, if so, how much? Did education unfit workers for their lot, or did it make them more accepting of it?

19. James Pillans, Contributions to the Cause of Education (London, I856), pp. 259-60; quotations come from a section originally published in 1836 as Three Lectures on the Proper Objects and Methods of Education in Reference to the Different Orders of Society.

20. Wilson, op. cit. (note I6), pp. 7, I2.

21. 'Country Gentleman', op. cit. (note 4), pp. I6-17.

22. [Archibald Alison], "Secular and Religious Education", Blackwood's Edinburgh Magazine, 45 (1839), 275-284 (p. 277).

23. 'Country Gentleman', op. cit. (note 4), p. 9.

24. Foster, op. cit. (note 5), p. I57.

25. Richard Dawes, Mechanics' Institutes and Popular Education (London, 1856), pp. I4-15.

26. 'Country Gentleman', op. cit. (note 4), p. I4.

27. This emphasis upon an interest in social control, it should be emphasized, is not a 'psychological' interpretation; it does not pretend to know what was 'in the heads' of proponents of popular education. However, those who propose 'philanthropy' as an explanatory concept would do well to consider the terms in which this motive was often expressed, e.g., by the philanthropist-reformer Kay-Shuttleworth: "The poor might thus [i.e., through education] be also made to understand their political position in society, and the duties that belong to it, ... [that] they are infinitely more interested in the preservation of public tranquility than any other class of society; that mechanical inventions and discoveries are always supremely advantageous to them ....”. (Kay-Shuttleworth, op. cit., note I2, p. 98, quoting the economist McCulloch.) Cf. Richard Johnson, "Educational Policy and Social Control in Early Victorian England", Past and Present, 49 (1970), 96-I 19.

28. Foster, op. cit. (note 5), p. I44.

29. Some of this pervasive rhetoric is presented, and its consequences in the curriculum demonstrated, by Shapin and Barnes, "Science, Nature and Control: Interpreting Mechanics' Institutes", Social Studies of Science, 7 (1977), forthcoming; repr. in part in Schooling and Capitalism, ed. Open University (London, 1976). 
30. [Archibald Alison], "Progress of Social Disintegration. No. I. The Schoolmaster", Blackwood's Edinburgh Magazine, 35 (1834), 228-248, p. 240.

31. Ibid., p. 243. According to Alison, these remarks were made by "the operatives of Manchester ... in one of their public manifestoes, in allusion to the Penny Magazine, and such productions".

32. See Appendix: Note on Sources and Methods.

33. "Lessons on Objects", Quarterly fournal of Education, I (I831), I 5I-I6I, p. I52.

34. Quoted in David Layton, Science for the People: The Origins of the School Science Curriculum in England (London, 1973), p. 25. Layton, especially chs, ii-v, is a superb source of material, upon which we have partly relied for the following paragraph.

35. "Edinburgh Sessional School", Quarterly fournal of Education, I (I831), 78-83, p. 82. Cf. John Wood, Account of the Edinburgh Sessional School (Edinburgh, I828).

36. Richard Dawes, quoted in Layton, op. cit. (note 34), p. 42.

37. The restricted experience which the lower orders, children and adults, had of the real variety of natural objects and phenomena could be adduced as an explanation of errors in their thought and moral make-up; cf. "Lessons on Objects", op. cit. (note 33), pp. I53-I 54 .

38. See, especially, the excellent exposition of the role of botany in Henslow's teaching, in Layton, op. cit. (note 34), ch. iii; "On Teaching the Natural Sciences in Schools", Quarterly Fournal of Education, 3 (1832), 26I-270, p. 266: “. . . By 'natural science', as taught at a school, we mean only that foundation of sensuous impressions on which all future scientific knowledge must be raised".

39. Maria and R[ichard] L[ovell] Edgeworth, Essays on Practical Education (New ed., London, I815; orig. publ. I798). vol. ii, p. 95; the resonance here with the plan in Plato's Republic is very striking.

40. Ibid., vol. i. p. 91 ; vol. ii. pp. I02-103.

4I. Ibid., vol. ii. p. 236.

42. Ibid., vol. ii. p. I 10.

43. Ibid., vol. ii. p. I3I.

44. Ibid., vol. ii. p. 249.

45. Pillans, op. cit. (note I9), pp. 263-264, 266.

46. Wilson, op. cit. (note I6), p. I2.

47. Ibid.

48. Edgeworth, op. cit. (note 39), vol. ii. pp. 424-425.

49. Wilson, op. cit. (note I6), p. I2.

50. Pillans, op. cit. (note I9), p. 262.

5I. Ibid.

52. Ibid., p. 263.

53. Cf. G. E. Davie, The Democratic Intellect: Scotland and Her Universities in the Nineteenth Century (2nd ed., Edinburgh, 1964), pp. I50-I68. On the 'mere mental mechanics' of algebra, see the eloquent Thomas Carlyle, "Signs of the Times", Critical and Miscellaneous Essays, vol. ii (London, I889), pp. 32I-322.

54. Wilson, op. cit. (note I6), p. I3.

55. In examining the privileged position of scientific subjects in the banausic tradition and their under-utilization in the gnostic tradition, one is brought up against an enduring public image of science as a body of hard facts and ascertained laws. It is therefore well to remind the non-scientist of what every practising scientist knows: that science is a corpus of provisional facts and tentative ways of accounting for them. The role of the gnostics in perpetuating this public image is well worth exploring. 


\section{Oxford Review of Education}

56. P. M. Rattansi, "Paracelsus and the Puritan Revolution", Ambix, II (1963), 23-32; Charles Webster, The Great Instauration: Science, Medicine and Reform I626-I660 (London, 1975), esp. pt. iii; Steven Shapin, "Phrenological Knowledge and the Social Structure of Early Nineteenth-Century Edinburgh", Annals of Science, 32 (1975), 219-243.

57. E.g., Bertrand Russell, On Education (London, 1926); Karl Mannheim, Introduction to the Sociology of Education (London, 1962); William Jolly, ed., Education: Its Principles and Practice as Developed by George Combe (London, I879).

58. Mary Douglas, Natural Symbols (London, 1970), esp. ch. v.

59. Arthur Jensen, Genetics and Education (London, 1972).

60. Basil Bernstein, Class, Codes and Control, vol. i (London, 1971).

61. E.g., Alan F. Blum, "Positive Thinking", Theory and Society, I (1974), 245-269; Blum, Theorizing (London, 1974); P. McHugh, S. Raffel, D. Foss, A. Blum, On the Beginning of Social Inquiry (London, 1974).

62. In certain contexts it would be appropriate to add women to this group; certainly, Victorian male reaction to feminism characterized women's mentality as banausic. See, Carroll Smith-Rosenberg and Charles Rosenberg, "The Female Animal: Medical and Biological Views of Woman and Her Role in Nineteenth-Century America", fournal of American History, 60 (1973), 332-356; Joan Burstyn, "Education and Sex: The Medical Case Against Higher Education for Women in England, 1870-1900," Amer. Phil. Soc., Proceedings, II7 (1973), 79-89.

63. Claude Lévi-Strauss, The Savage Mind (London, 1966), ch. i; C. R. Hallpike, "Is there a Primitive Mentality?", Man, II (1976), 253-270.

64. Ibid. Lévi-Strauss likens 'mythical thought' to the work of the bricoleur. He is a sort of handyman, whose genius it is to solve the technical problems of each 'odd-job' with whatever is at hand in his tool-kit, nothing in which is purpose-made. 
http://www.jstor.org

\title{
LINKED CITATIONS
}

- Page 1 of 2 -

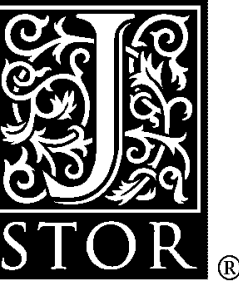

You have printed the following article:

Head and Hand: Rhetorical Resources in British Pedagogical Writing, 1770-1850

Steven Shapin; Barry Barnes

Oxford Review of Education, Vol. 2, No. 3, History and Education. Part One. (1976), pp. 231-254.

Stable URL:

http://links.jstor.org/sici?sici=0305-4985\%281976\%292\%3A3\%3C231\%3AHAHRRI\%3E2.0.CO\%3B2-K

This article references the following linked citations. If you are trying to access articles from an off-campus location, you may be required to first logon via your library web site to access JSTOR. Please visit your library's website or contact a librarian to learn about options for remote access to JSTOR.

\section{Notes and References}

\author{
${ }^{27}$ Educational Policy and Social Control in Early Victorian England \\ Richard Johnson \\ Past and Present, No. 49. (Nov., 1970), pp. 96-119. \\ Stable URL: \\ http://links.jstor.org/sici?sici=0031-2746\%28197011\%290\%3A49\%3C96\%3AEPASCI\%3E2.0.CO\%3B2-V \\ ${ }^{29}$ Science, Nature and Control: Interpreting Mechanics' Institutes \\ Steven Shapin; Barry Barnes \\ Social Studies of Science, Vol. 7, No. 1. (Feb., 1977), pp. 31-74. \\ Stable URL: \\ http://links.jstor.org/sici?sici=0306-3127\%28197702\%297\%3A1\%3C31\%3ASNACIM\%3E2.0.CO\%3B2-M

\section{${ }^{61}$ Positive Thinking} \\ Alan F. Blum \\ Theory and Society, Vol. 1, No. 3. (Autumn, 1974), pp. 245-269. \\ Stable URL: \\ http://links.jstor.org/sici?sici=0304-2421\%28197423\%291\%3A3\%3C245\%3APT\%3E2.0.CO\%3B2-9
}

\footnotetext{
${ }^{62}$ The Female Animal: Medical and Biological Views of Woman and Her Role in Nineteenth-Century America

Carroll Smith-Rosenberg; Charles Rosenberg

The Journal of American History, Vol. 60, No. 2. (Sep., 1973), pp. 332-356.

Stable URL:

http://links.jstor.org/sici?sici=0021-8723\%28197309\%2960\%3A2\%3C332\%3ATFAMAB\%3E2.0.CO\%3B2-J
}

NOTE: The reference numbering from the original has been maintained in this citation list. 
http://www.jstor.org

\section{LINKED CITATIONS \\ - Page 2 of 2 -}

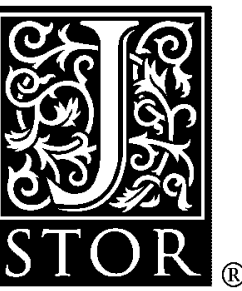

\section{${ }^{62}$ Education and Sex: The Medical Case against Higher Education for Women in England, 1870-1900}

Joan N. Burstyn

Proceedings of the American Philosophical Society, Vol. 117, No. 2. (Apr. 10, 1973), pp. 79-89.

Stable URL:

http://links.jstor.org/sici?sici=0003-049X\%2819730410\%29117\%3A2\%3C79\%3AEASTMC\%3E2.0.CO\%3B2-O

\section{${ }^{63}$ Is There a Primitive Mentality?}

C. R. Hallpike

Man, New Series, Vol. 11, No. 2. (Jun., 1976), pp. 253-270.

Stable URL:

http://links.jstor.org/sici?sici=0025-1496\%28197606\%292\%3A11\%3A2\%3C253\%3AITAPM\%3E2.0.CO\%3B2-T

\section{${ }^{64}$ Is There a Primitive Mentality?}

C. R. Hallpike

Man, New Series, Vol. 11, No. 2. (Jun., 1976), pp. 253-270.

Stable URL:

http://links.jstor.org/sici?sici=0025-1496\%28197606\%292\%3A11\%3A2\%3C253\%3AITAPM\%3E2.0.CO\%3B2-T

NOTE: The reference numbering from the original has been maintained in this citation list. 